\title{
Analysis of PVE test methods based on different engine control systems
}

\author{
Xionghui Zou*, Lihui Wang, Le Liu, Peilin Geng, and Jingyuan Li \\ China Automotive Technology \& Research Center Co., Ltd., Tianjin 300300 China
}

\begin{abstract}
Keywords: China 6 Emission Standard, OBD, PVE, Diagnostic Trouble Code (DTC).

Abstract. According to the requirements of PVE proposed in the China 6 Emission Standard for light-duty vehicles, this paper compares a fault code respectively from cooling system monitoring, oxygen sensor monitoring and integrated component monitoring of Spark Ignition Engines, and analyzes the diagnosis principles and simulation methods under three engine control systems in detail. The results show that the fault diagnosis principles for UAES system and Bosch system are similar, and the simulation methods can learn from each other. The fault diagnosis principles of the two systems are different from those of Delphi system, and the simulation methods depend on the fault failure mode.
\end{abstract}

\section{Instruction}

With the continuous growth of vehicle ownership in China, the emission of vehicle pollutants ranks first in the world. By tightening the emission standards of vehicles, it can effectively limit the emissions of single vehicle pollutants and inhibit the impact on environmental pollution. China 6 Emission Standard for light-duty vehicles[1] was officially released on December 23, 2016, and will be implemented nationwide on July 1, 2020. Compared with China 5 Emission Standard for light-duty vehicles, the emission limits and test methods are more stringent [2], and the requirements of production vehicle evaluation (PVE) test are put forward.

Based on the China 6 Emission Standard for light-duty vehicles, this paper compares a fault code respectively from cooling system monitoring, oxygen sensor monitoring and integrated component monitoring of Spark Ignition Engines, and analyzes the diagnosis principles and simulation methods under three engine control systems in detail.

\section{PVE test requirements for OBD system}

The OBD system has standardization protocols, but the protocols adopted in different regions are different, such as the ISO standards in Europe and the SAE standards in the United States.

\footnotetext{
* Corresponding author: zouxionghui@catarc.ac.cn
} 
To some extent, the requirements of ISO standard and SAE standard for the underlying protocol are equivalent, thus forming a globally unified standardized OBD system. In 1988, SAE issued the standardized on-board diagnostic protocol. In 1991, CARB issued the OBD I standard, and in 1994-1996, the OBD II[3] standard was introduced by CARB. After continuous revision in 2002 to 2012, the widely used OBD II standard has been gradually formed. The relevant requirements of OBD in China 6 Emission Standard refer to the OBD II standards of the United States.Europe has formed its own EOBD[4] standard since 2000, and after development and improvement, it is also approaching the US OBD II standard.

PVE test is a new requirement of OBD certification in China 6 Emission Standard. PVE test consists of three parts:

the verification of the standardization of $\mathrm{J} 1$.

the verification of the monitoring requirements of $\mathrm{J} 2$.

the verification of the monitoring performance in in-used vehicles of $\mathrm{J} 3$.

The main purpose of $\mathrm{J} 1$ test is to verify that the vehicle can communicate with the scan tool normally, and the OBD system meets the relevant protocol requirements of SAE J1979[5]. J2 test requires to verify all fault codes of the vehicle. The OBD system shall be able to detect the fault, turn on MIL light and store corresponding confirmation and permanent fault codes. J3 test is mainly to collect IUPR data of in-used vehicles.

The China 6 Emission Standard requires enterprises to submit the annual PVE test plan before April 1 of each year, and complete the standardization verification of J1 within 3 months after production. J2 verification shall be completed within 6 months, and J3 verification and report of in-used vehicles shall be completed within 12 months.

\section{Comparative analysis of fault principle and simulation method}

At present, the main engine control system in China is provided by UAES, Delphi and Bosch.Based on the difference engine control system, this section compares a fault code respectively from cooling system monitoring, oxygen sensor monitoring and integrated component monitoring of Spark Ignition Engines, and analyzes the fault diagnosis principle and simulation method of three engine control systems.

\subsection{Cooling system monitoring}

The OBD system shall monitor engine coolant temperature (ECT) sensor circuit continuity, signal out of range and rationality. If the circuit is open or the value is out of range, the OBD system shall detect a fault.

Table 1. Comparison the simulation methods for P0119 fault code.

\begin{tabular}{l|l|l|l}
\hline $\begin{array}{l}\text { Code } \\
\text { name }\end{array}$ & $\begin{array}{l}\text { Control } \\
\text { system }\end{array}$ & Code description & \multicolumn{1}{c}{ Simulation method } \\
\hline P011 & UAES & $\begin{array}{l}\text { Engine Coolant } \\
\text { Temperature } \\
\text { Sensor 1 Circuit } \\
\text { Intermittent }\end{array}$ & $\begin{array}{l}\text { 1, Seak at least 8 hours. Plug and insert the short-circuit pin of the sensor } \\
\text { signal for more than 20s with high frequency, until the pending } \\
\text { codenerated } \\
\text { 3, Repeat the above steps once, report confirmation and } \\
\text { permanent fault code, and turn on the malfunction indicator. }\end{array}$ \\
\hline
\end{tabular}




\begin{tabular}{|c|c|c|}
\hline Delphi & $\begin{array}{l}\text { Abnormal } \\
\text { coolant } \\
\text { temperature in } \\
\text { low temperature } \\
\text { environment }\end{array}$ & $\begin{array}{l}\text { 1, Soak at least } 10 \text { hours. } \\
\text { 2, Idle until ECT reaches } 50^{\circ} \mathrm{C} \text {, pull out the pin of the coolant } \\
\text { temperature sensor in the connecting box and insert a low } \\
\text { voltage signal at the same time in ECU side. } \\
\text { in } 3 \text {, Drive the vehicle and reduce the voltage rapidly until the } \\
\text { are } \\
\text { coolant temperature exceeds } 110^{\circ} \mathrm{C} \text {, and drive the vehicle until } \\
\text { the pending code is reported } \\
\text { 4, Repeat the above steps once, report confirmation and } \\
\text { permanent fault code, and turn on the malfunction indicator. }\end{array}$ \\
\hline Bosch & $\begin{array}{l}\text { ECT signal } \\
\text { gradient } \\
\text { monitoring }\end{array}$ & $\begin{array}{l}\text { 1, Key off, open the ECT pin and connect a variable resistant at } \\
\text { ECU side. } \\
2, \text { Start and adjust the resistance value between } 45 \mathrm{k} \text { ohms and } \\
100 \text { ohms at the frequency of } 2 \sim 3 \mathrm{~Hz} \text { until a pending code is } \\
\text { reported. } \\
3, \text { Repeat the above steps once, report confirmation and } \\
\text { permanent fault code, and turn on the malfunction indicator. }\end{array}$ \\
\hline
\end{tabular}

Table 1 shows the description of P0119 fault code and comparison the simulation methods under three different engine control systems. According to the definition of diagnostic trouble code given in SAE J2012-2007[6], P0119 is a fault of engine coolant temperature sensor 1 circuit intermittent.

It can be seen from table 1 that different control systems have different descriptions for the same trouble code. For UAES system, it means the unreasonable voltage of coolant temperature sensor 1 . When the difference between the measured original signal and filtered signal of the coolant temperature sensor voltage is greater than the calibration threshold, the fault code is reported after the lasting duration reaches the calibration limit.

For Delphi system, it means abnormal high coolant temperature in low temperature environment. When the vehicle is started and the coolant temperature reaches the enable condition value, if the coolant temperature exceeds the high temperature threshold for a period of time, the code is set. During test, Engine alarms for high coolant temperature, the coolant fan is still working. Figure 1 is the schematic diagram of diagnosis for P0119 in Delphi system.

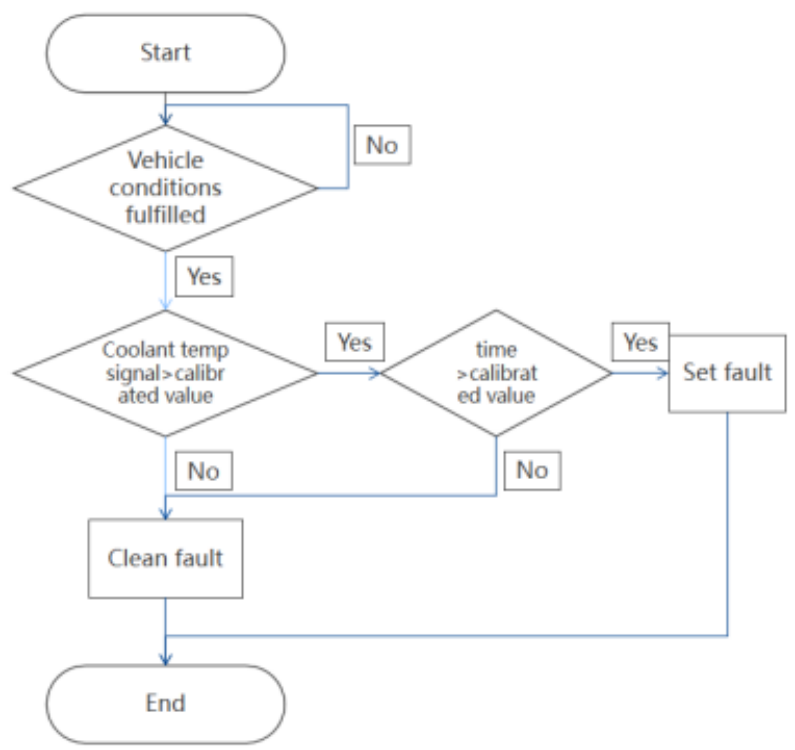

Fig. 1. Schematic diagram of diagnosis for P0119 in Delphi system. 
For Bosch system, it means the fault of gradient of the temperature signal. If the absolute value of the temperature gradient exceeds a calibrated threshold for a calibrated period of time, a fault will be set. The schematic diagram of the diagnosis is shown in Figure 2.

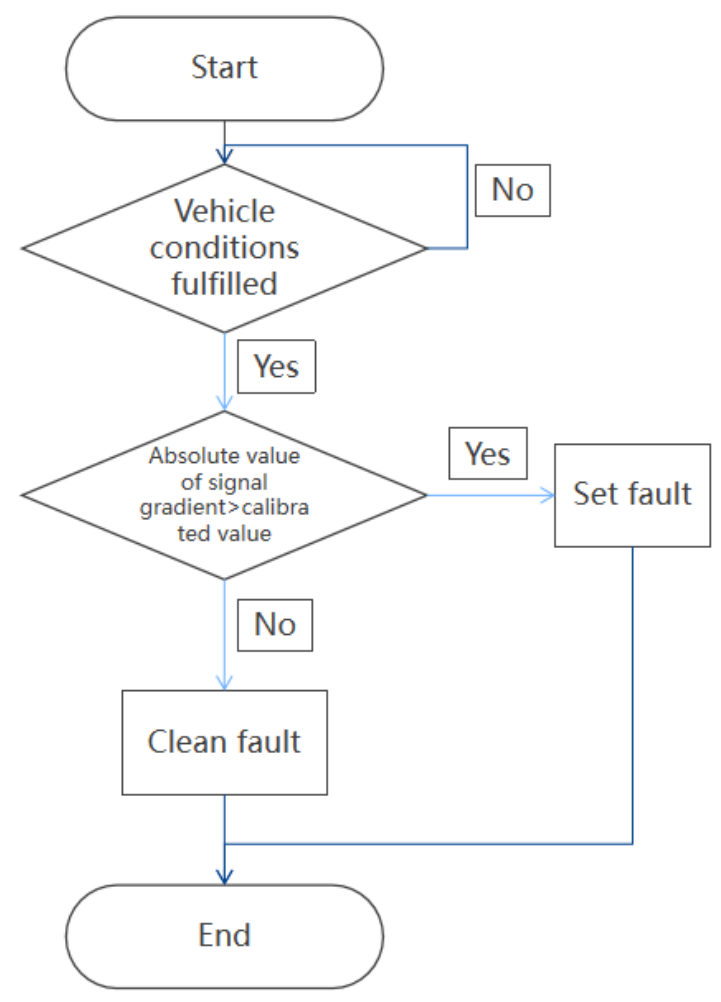

Fig. 2. Schematic diagram of diagnosis for P0119 in Bosch system.

For UAES and Delphi system, P0119 fault needs to be diagnosed during cold start, which is not required in Bosch system. Therefore, different engine control systems have different definitions of the same fault code, resulting in different diagnosis strategies. Even if the same engine control system, the difference of engine structure and components will lead to the change of threshold value, resulting in different simulation methods.

\subsection{Exhaust sensor monitoring}

According to the requirements of China 6, the OBD system shall monitor the output voltage, activity and response rate of the front and rear oxygen sensors. For heated oxygen sensor, OBD system shall monitor the heating performance. For other types of sensors, the same requirements are also required to be monitored as oxygen sensors.

Table 2 shows the description of P2196 fault code and comparison the simulation methods under three different engine control systems. According to the definition of diagnostic trouble code given in SAE J2012-2007, P2196 is O2 Sensor Signal Biased / Stuck Rich. For UAES system, it means O2 Sensor Signal Stuck Rich. After the engine start, the signal value of front oxygen sensor is between the upper limit of signal at circuit break and the limit of signal high. At this time, the rear oxygen sensor shows that the mixture is lean, and the system sets the code when the diagnostic conditions are met. The schematic diagram of this code diagnosis is shown in Figure 3. 


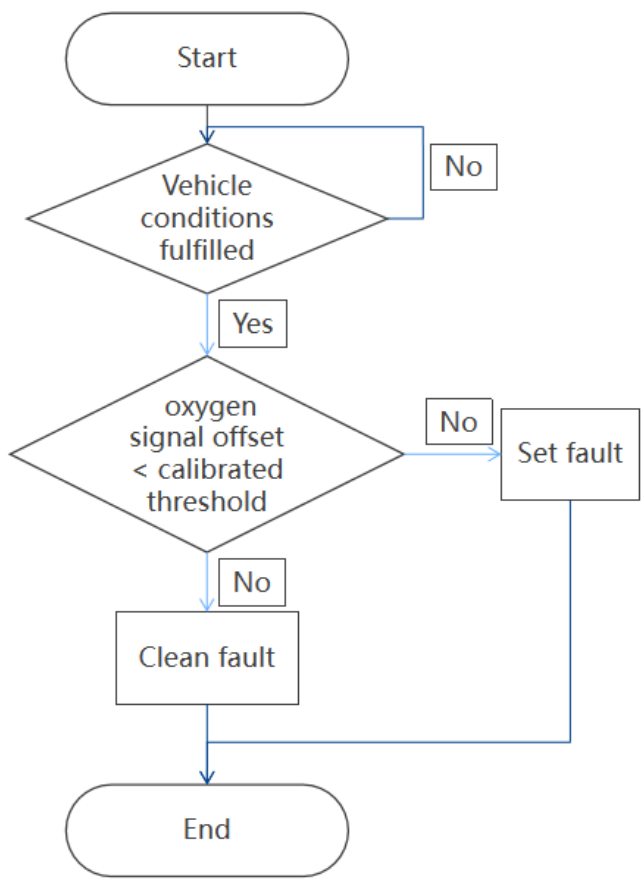

Fig. 3. Schematic diagram of diagnosis for $\mathrm{P} 2196$ in UAES system.

Table 2. Comparison the simulation methods for P2196 fault code.

\begin{tabular}{|c|c|c|c|}
\hline \begin{tabular}{l|} 
Code \\
name
\end{tabular} & $\begin{array}{l}\text { Control } \\
\text { system }\end{array}$ & Code description & Simulation method \\
\hline \multirow{3}{*}{ P2196 } & UAES & $\begin{array}{l}\text { O2 Sensor Signal } \\
\text { Biased/Stuck } \\
\text { Rich Bank } \\
\text { Sensor } 1\end{array}$ & $\begin{array}{l}\text { 1, Key off, open the } \mathrm{O} 2 \text { signal pin and connect a fixed voltage at } \\
\text { ECU side. } \\
\text { 2, Start, drive until the fault occurs. } \\
\text { 3, Repeat the above steps once, report confirmation and permanent } \\
\text { fault code, and turn on the malfunction indicator. }\end{array}$ \\
\hline & Delphi & $\begin{array}{l}\text { O2 Sensor Signal } \\
\text { Biased/Stuck } \\
\text { Rich during } \\
\text { Deceleration }\end{array}$ & $\begin{array}{l}\text { 1, Key off, install the oxygen sensor fault simulator, enter the signal } \\
\text { constant setting mode, and set a fixed voltage. } \\
\text { 2, Start and drive the vehicle, enter DFCO mode, repeat a few } \\
\text { times, until the fault occurs. } \\
3 \text {, Repeat the above steps once, report confirmation and permanent } \\
\text { fault code, and turn on the malfunction indicator. }\end{array}$ \\
\hline & Bosch & $\begin{array}{l}\text { O2 Sensor Signal } \\
\text { Biased/Stuck } \\
\text { Rich Bank } \\
\text { Sensor } 1\end{array}$ & $\begin{array}{l}\text { 1, Key off, open the } \mathrm{O} 2 \text { signal pin and connect a fixed resistance at } \\
\text { ECU side. } \\
2 \text {, Start the vehicle, release the accelerator after driving the vehicle } \\
\text { at a certain speed, repeat for many times until the pending fault } \\
\text { code is reported. } \\
3 \text {, Repeat the above steps once, report confirmation and permanent } \\
\text { fault code, and turn on the malfunction indicator. }\end{array}$ \\
\hline
\end{tabular}

For Delphi system, it means O2 Sensor Signal Stuck Rich during Deceleration. During deceleration, due to the large amount of oxygen in the exhaust gas, the mixture is lean, the voltage of the oxygen signal is low. If the voltage of the oxygen signal is higher than the calibrated limit and maintained for a calibrated period, the fault is set. The key for this fault simulation is that the engine must work under the condition of deceleration. 
For Bosch system, it means O2 Sensor Signal Biased Rich. When the characteristic curve of oxygen signal deviates to the rich and the value exceeded the calibration limit (the characteristic curve is shown in Figure 4), the fault code is detected. When the fault is diagnosed, the vehicle coolant temperature should be normal and the engine should run stably near the theoretical air-fuel ratio.

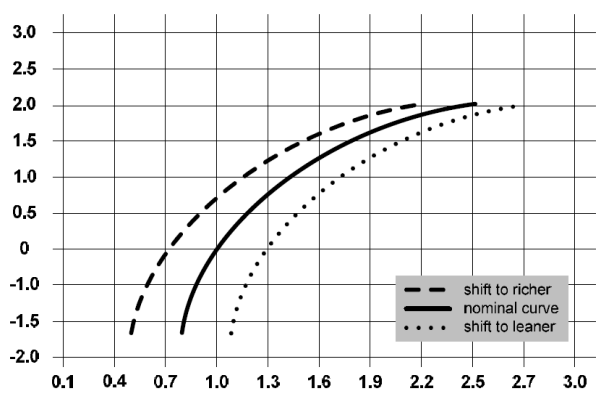

Fig. 4. The function of front oxygen sensor signal and air fuel ratio.

\subsection{Integrated component monitoring}

The OBD system shall monitor all components of the electronic power system that can cause emissions to exceed the OBD threshold due to faults, or that component is part of the diagnostic strategy of other monitoring components / systems that directly or indirectly provide input to or receive instructions from the on-board computer or intelligent device[1].

The input components to be monitored shall include (but not limited to) speed sensor, crankshaft angle sensor, knock sensor, throttle position sensor, camshaft position sensor, sensor and module providing signals to the power control system or other actuators.

The output components / systems to be monitored shall include (but not limited to) idle speed control system, variable manifold system, electronic components for supercharging or exhaust turbocharging, by-pass valve for catalyst heating, automatic transmission solenoid valve or control system, etc.

Table 3 shows the description of P0451 fault code and comparison the simulation methods under three different engine control systems. According to SAE J2012-2007, P0451 is Evaporative Emission System Pressure Sensor/Switch Range/Performance.

P0451 fault of UAES system and Bosch system both contain three failure modes:

Rationality - signal offset.

Rationality - incremental check.

Rationality - signal oscillation.

For the tank pressure signal oscillation fault, UAES system measures the tank pressure signal oscillation amplitude by checking the allocated evaluation time. Under normal circumstances, the pressure signal fluctuation should be below the calibrated threshold. If the pressure signal noise is too large, and the signal fluctuation fails to be lower than the calibration threshold value for a calibration period, P0451 fault will be reported.The schematic diagram of this code diagnosis is shown in Figure 5. 


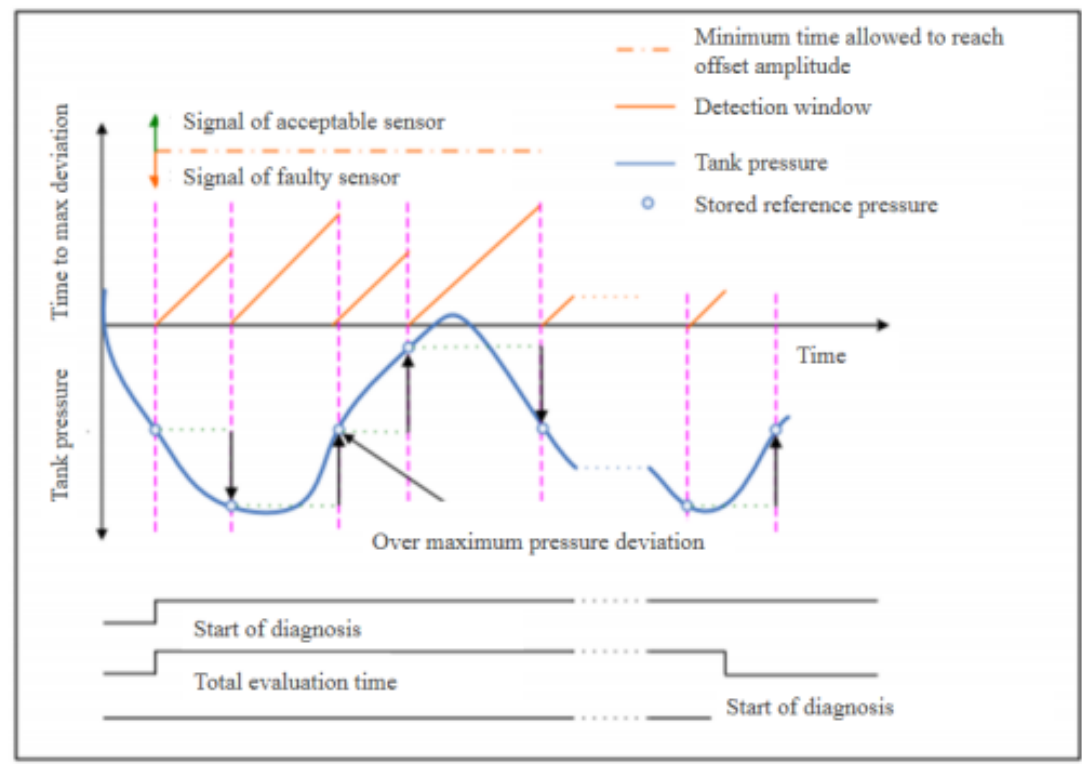

Fig. 5. Schematic diagram of signal oscillation rationality fault of fuel tank pressure sensor in UAES system.

Table 3. Comparison the simulation methods for P0451 fault code.

\begin{tabular}{|c|c|c|c|}
\hline $\begin{array}{l}\text { Code } \\
\text { name } \\
\end{array}$ & \begin{tabular}{|l|}
$\begin{array}{l}\text { Control } \\
\text { system }\end{array}$ \\
\end{tabular} & Code description & Simulation method \\
\hline \multirow{3}{*}{ P0451 } & UAES & $\mid \begin{array}{ll}\text { EVAP } & \text { System } \\
\text { Pressure } & \text { Sensor } \\
- & \text { Oscillation } \\
\text { Check } & \end{array}$ & $\begin{array}{l}\text { 1, Key off, open tank pressure signal pin and connect a variable } \\
\text { resistant at ECU side. } \\
2, \text { Key on, adjust the resistance at high frequency between } 0 \text { and } \\
100 \mathrm{k} \text { ohms for a period of time until the fault is reported. } \\
3 \text {, Repeat the above steps once, report confirmation and } \\
\text { permanent fault code, and turn on the malfunction indicator. }\end{array}$ \\
\hline & Delphi & $\begin{array}{ll}\text { EVAP } & \text { System } \\
\text { Pressure } & \text { Sensor } \\
- \text { Stuck } & \text { Check }\end{array}$ & $\begin{array}{l}\text { 1, Key off, open tank pressure sensor pin and connect a fixed } \\
\text { voltage at ECU side. } \\
\text { Start the vehicle when the engine is hot. } \\
2 \text {, Drive the vehicle, wait for closing the purge valve after the } \\
\text { flow of the carbon canister cleaning valve is greater than the } \\
\text { calibrated limit, and the failure counter will increase once after } \\
10 \text { s; } \\
3 \text {, Repeat step } 3 \text { for four times and then report the code. }\end{array}$ \\
\hline & Bosch & $\mid \begin{array}{ll}\text { EVAP } & \text { System } \\
\text { Pressure } & \text { Sensor } \\
- & \text { Oscillation } \\
\text { Check } & \end{array}$ & $\begin{array}{l}\text { 1, Key off, open tank pressure signal pin and connect a variable } \\
\text { resistant at ECU side. } \\
2 \text {, Key on, adjust the resistance at high frequency between } 0 \text { and } \\
100 \mathrm{k} \text { ohms for a period of time until the fault is reported. } \\
3 \text {, Repeat the above steps once, report confirmation and } \\
\text { permanent fault code, and turn on the malfunction indicator. }\end{array}$ \\
\hline
\end{tabular}

The diagnosis principle of the tank pressure signal oscillation rationality fault in Bosch system is similar to UAES, and the fault simulation method is same.

The fault of P0451 in Delphi system is the signal of fuel tank pressure sensor stuck. During the fuel evaporation diagnostic test, the tank pressure will change significantly during the vacuum stage. If the change of the pressure in the tank is less than the calibrated limit value and lasts for a calibration period, the fault will be detected. It can be seen that 
the fault simulation method of Delphi system is quite different from UAES and Bosch system.

The signal oscillation fault code of tank pressure sensor in Delphi system is P0454. During the fuel evaporation diagnostic test, if the fuel tank pressure signal changes beyond the calibrated limit within a given time, the fault is detected. The fault can be simulated by inputting a triangle wave with fixed frequency.

\section{Conclusion}

For the same fault code, SAE J2012 defines the meaning and scope of the fault. In the actual using process, the same fault code is divided into multiple fault failure modes, and the engine control system manufacturer can define according to their own or the buyer's requirements.

Based on the requirements of PVE test in China 6 for light-duty vehicles, this paper compares a fault code respectively from cooling system monitoring, exhaust sensor monitoring and integrated component monitoring, and analyzes the fault description and fault simulation methods of three engine control systems in detail. The results are below:

1) Different engine control systems have different failure modes with the same fault code, resulting in different fault simulation methods.

2) Some fault code diagnosis principles of UAES system and Bosch system are similar, and simulation methods can learn from each other.

3) Most of the fault diagnosis principles of Delphi system are quite different from those of UAES and Bosch system, and the simulation methods depends on the failure mode.

This work was financially supported by the Construction of Public Service Platform for Vehicle Emission/Energy Consumption Information System(Improvement of public service capacity of Industrial Technology Foundation 2018), the Integrated Technology of Particulate Matter Capture and Clean Emission for Gasoline Vehicles Projects (No.: 2017YFC0211004 and 2017YFC0211005).

\section{Reference}

1. GB 18352.6-2016. Limits and measurement methods for emissions form light-duty vehicles (CHINA 6)

2. Ding Li, Zou Xionghui, Dai Chunbei.etc. Comparison the Difference Between China VI and China V Emission Standards of Light Vehicles. Small internal combustion engine and vehicle technique. 2019.3

3. CARB. Modifications to Malfunction and Diagnostic System Requirements for 1994 and Subsequent Model-Year Passenger Cars, Light-Duty Trucks, and Medium-Duty Vehicles and Engines (OBD II): Title13, California Code of Regulations, Section 1968.1[S]

4. Wang Lihui, Liu Le, Ling Jian. Research on production vehicle evaluation (PVE) test method based on OBD system. Small internal combustion engine and vehicle technique. 2019.5

5. E/E Diagnostic Test Modes. SAE J1979-2007

6. (R) Diagnostic Trouble Code Definitions,SAE J2012-2007 